\title{
Training of Microcontrollers Using Remote Experiments
}

\author{
http://dx.doi.org/10.3991/ijoe.v8iS4.2270 \\ O. Dziabenko ${ }^{1}$, A.Rojko ${ }^{2}$, I. Angulo ${ }^{1}$, J. Garcia-Zubia ${ }^{1}$, and P. Orduna ${ }^{1}$ \\ ${ }^{1}$ University of Deusto, Bilbao, Spain, ${ }^{2}$ University of Maribor, Slovenia
}

\begin{abstract}
Nowadays lifelong education is a necessity for all professionals from electro-mechanical industry. Creating of industrial training that delivers up-to-date knowledge with user friendly educational methods requests a close cooperation of industry and educational institutions. This paper presents results of project E-Learning and Practical Training of Mechatronics and Alternative Technologies in Industrial Community (E-PRAGMATIC) for 7 European countries. The need analysis and developed training will be described. The three courses: (a) Introduction to Microcontroller, (b) 8-bit Microcontrollers Advanced Course, (c) Low-cost platform to provide LAN / WAN connectivity for embedded systems, developed by University of Deusto, will be provided in case study format.
\end{abstract}

Index Terms-vocational training, remote experiments, microcontrollers, alternative technology, e-learning.

\section{INTRODUCTION}

Today's economy bases on well-educated, creative human capital secured by a globally competitive education system that includes higher education, vocational education and training, and continuing education and training. Contemporary education and training needs continuous content and methodology update with strong industry input. Modernizing curricula in this way is essential in meeting skills gaps and keeping students and employees competitive. "Education and training" and "work" are no longer two separate words, they are integrated into a single flexible lifelong learning process that should develop job-specific skills with essential transversal part [1]. The politicians and policy makers in all part of the world forces STEM (Science, technology, engineering and Mathematics) education by billions funds. For example, the program 'College to Careers'(IL,USA) [2] refocus a training to reduce or even to vanish skills gap for youth, since they will not have or have not sufficient time of internship in industry, and elderly employees, which got their professional knowledge and basic education long time ago. European Union for these purposes established 2 programs: Grundtvig [3] for adult education and Leonardo da Vinci [3] for vocational education and training. In this paper the preliminary results of project "EPRAGMATIC:E-Learning and Practical Training of Mechatronics and Alternative Technologies in Industrial Community" [4] are presented. The project is supported by Lifelong Learning Programme of European Union [3].

\section{E-PRAGMATIC THEMATIC NETWORK AND LEARNING MODULES}

E-PRAGMATIC network (E-Learning and Practical Training of Mechatronics and Alternative Technologies in
Industrial Community) is an association of 13 regular and 6 associated partners from seven European countries. The network's partners are the educational institutions, chambers, enterprises and associations. The main aim of the network is modernizing mechatronics and engineering vocational training of the employed professionals, apprentices and trainees, by enhancing of the existing or establishing new in-company training approaches in the industry.

Based on survey (Feb. 2011) results, E-PRAGMATIC educational partners designed twenty one learning courses, from mechatronics and alternative technologies [5]. Courses are prepared and executed by University of Maribor, Slovenia; Poznan University of Technology, Poland; Delft University of Technology, Netherlands; Carinthia University of Applied Sciences, Austria; University of Applied Sciences Bern, Switzerland; and University of Deusto, Spain. The learning modules available for learners can be divided in three large groups: basics courses for providing background knowledge, courses on alternative and emerging technologies, and by industry requested courses. The courses requested directly by industry are: PC based measurement and control; Energy efficiency; Introduction to LabVIEW; PLC controllers and industrial networks; Introduction to microcontrollers and embedded systems; Advanced peripherals with microcontrollers; Robot programming; Material science; Industrial Ethernet; Microgrids: Stand-alone systems. The basic ones are covered by such courses as Electrical drives; Applied control theory, and Introduction to industrial robotics. The alternative and emerging technologies courses are introduced by follow courses: Solar electricity, Hybrid drives, Power electronics for electric cars Charging of the electric cars, Introduction to remote and online engineering; Wheeled mobile robots practical aspects of control and navigation, and Low cost Platform for Providing LAN/WAN Connectivity to Embedded Systems. These online courses are available on E-PRAGMATIC learning portal - eCampus [6]. All courses are in English language and some also in Spanish, Slovene, Polish and German language. Participant of the training, practicing technicians and engineers, are from more than 40 European companies from electromechanical field.

Through the project concrete solutions for industrial education were developed including contents of the courses, multimedia e-learning materials, an efficient learning management systems and application of remote working stations and experiment for practical part of the training. Applied education methodology will be revised by considering feedback obtained from the training participants. Based on gained experience, a long-term 
perspective of such education will be evaluated and some conclusion relevant also for regular education will be drawn.

The primary aim of the paper is presenting the learning modules developed by WebLab-Deusto team of University of Deusto during the E-PRAGMATIC project:

- Introduction to Microcontroller,

- 8-bit Microcontrollers Advanced Course,

- Low-cost platform to provide LAN / WAN connectivity for embedded systems.

All three courses are available in English and Spanish language.

\section{STRUCTURE OF THE LEARNING COURSES}

Ideally, the online course design should customize the learner experience to meet their goals and complement their personal learning styles. The general rules of building distance course teach us: (1) using a repetitive structure for each part of the module; (2) the pages containing the course material should be organized in a way that makes navigation easy, simple and consistent [7]. Based on this every course has the standardize structure: course summary presentation, its outline, educational objectives, target audience, preliminary knowledge and skills required from learners, and time necessary for execution of the courses.

Three courses addressed as a case study cover different families of 8-bit microcontrollers manufactured at Microchip Technology $\subset$. Nowadays microcontrollers allow automating of simple systems by performing simple processes responsible for automatic control of one or more actuators based on the capture of certain sensors. Current 8-bit microcontrollers apply from simple projects to complex ones - systems control including the latest industrial technologies of communication, at low cost and with minimal power consumption. The courses that are offered by WebLab-Deusto for learning PIC microcontrollers include three remote experiments. They manage:

- basic resources (digital inputs / outputs, timers, watchdog, etc.) in introductory course;

- complex peripherals such as PWM, ADC, Priority Interrupts, SPI and I2C buses, etc. in course of advanced peripherals and telecontrol;

- an embedded system from internet with Ethernet connectivity in last one.

The learner can start from beginning with Introduction to Microcontrollers, continue with 8-bit Microcontrollers Advanced Course, and finish with Low-cost platform to provide LAN / WAN connectivity for embedded systems. The training courses run in English and Spanish languages. The educator's support and help were provided during online E-PRAGMATIC training.

\section{INTRODUCTION TO MICROCONTROLLER}

The main purpose of the course to introduce different families of microcontrollers marketed by Microchip Technology $($ and to provide knowledge and skills required to create a project, based on devices belonging to the PIC18F family. The target audiences are electronic and automatic engineers as well students of professional and tertiary education in electronics.

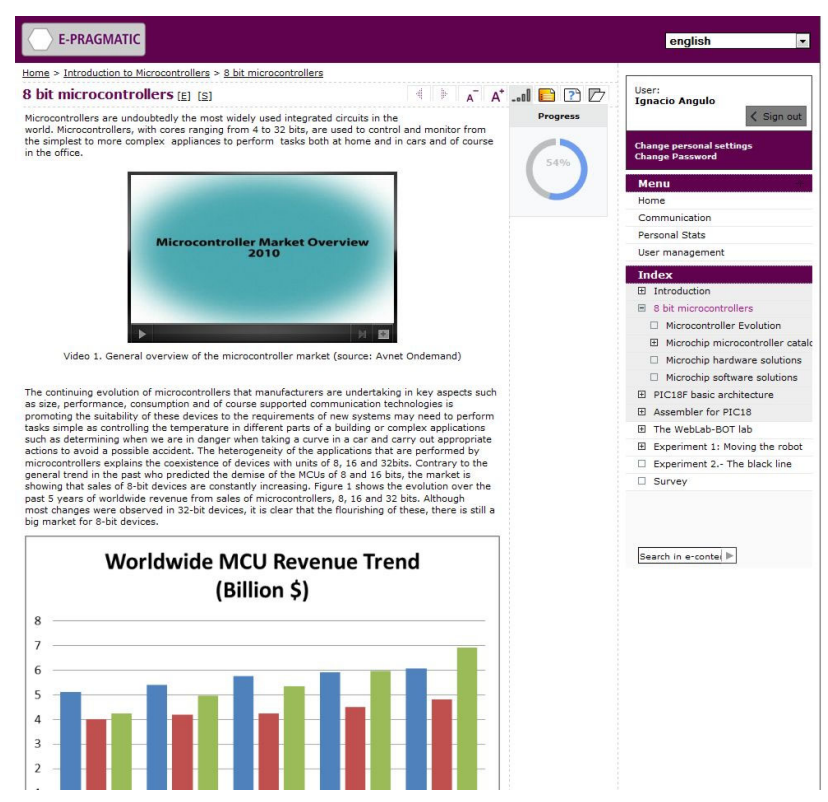

Figure 1. E-pragmatic Learning Portal.

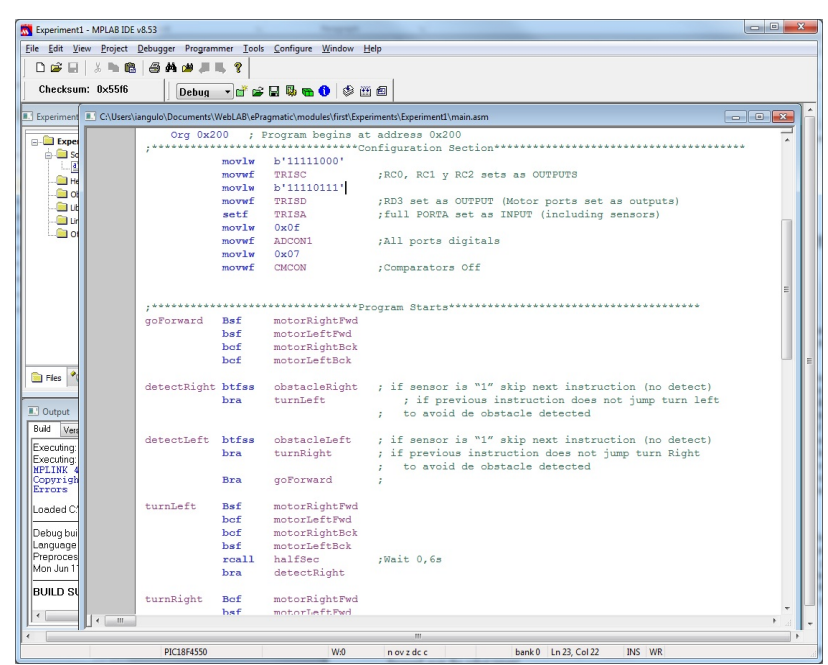

Figure 2. MPLAB Integrated Development Environment.

The theoretical content of course covers, generically, the history of microcontrollers in recent decades, the current market conditions and forecasts for the near future. Moreover, the first part of the content introduces the fundamentals of architecture adopted by major manufacturers, extending by the architecture of the $18 \mathrm{~F}$ family of microcontrollers from Microchip Technology $($, presenting the main hardware and software tools provided by the manufacturer.

The second part of the course aims to train students to develop independently a project based on microcontrollers handling digital inputs and outputs. This section examines the instruction set from microcontroller family detailing how to implement major control structures.

Finally the course includes real experimentation using the remote laboratory "WebLab-Deusto Bot" [9] provided by the University of Deusto. In final - third part, the course guides the students from a preliminary analysis of the project requirements through a debugging to a test in a real platform. 


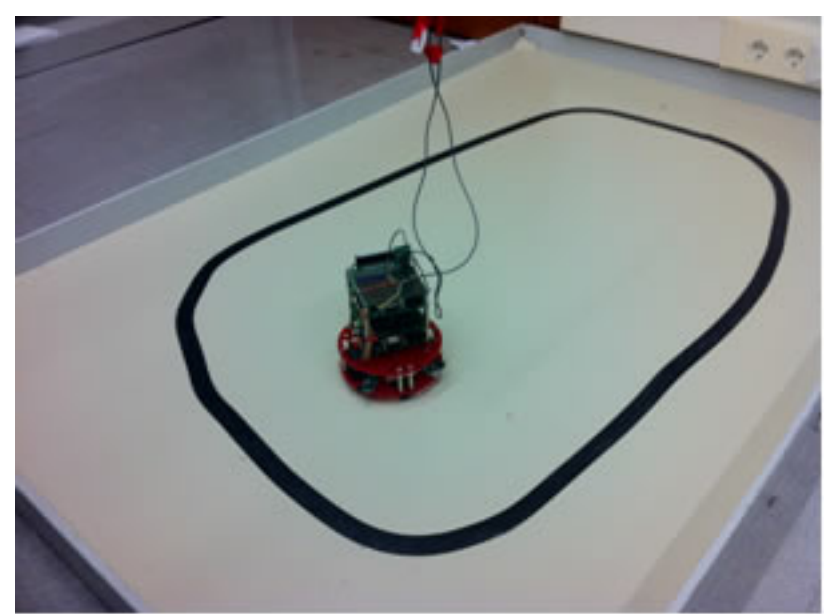

Figure 3. WebLab Deusto Bot.

To complete the course, students must perform two experiments consisting in a development of the firmware that manages the behavior of the mobile robot provided by the remote laboratory.

In the first experiment the robot should move randomly without colliding with walls of a mat. To execute the experiment the student should develop the project using the MPLAB Integrated Development Environment provided for free by Microchip Technology $($ to control two servos connected to wheels of the robot and two sensors that detect obstacles on the left or right of the robot trajectory. Once the project is built WebLab-Deusto Platform allows the student to program on the air the MCU that manages the robot and observe its behavior through a camera.

The second experiment adds the control of two infrared sensors to detect a black line beneath the robot. The purpose of this final experiment is to recognize the line on the floor and follow it to the end of the experiment. The task of students to write such code that robot finishes his path for as much as possible short time [8].

\section{8-BIT Microcontrollers AdVANCEd COURSE}

The main feature that distinguishes a microprocessor and a microcontroller are the resources integrated into the latter. This course identifies the most common microcontroller integrated peripherals and enters the $18 \mathrm{~F}$ family of microchip Technology ${ }^{\circledR}$ in order to train students in managing these resources.

Aim of the course is providing a methodology for a proper control of advanced peripherals including a microcontroller. The course instructs how to apply available resource, and mainly the datasheet provided by manufacturer of microcontroller, to develop advanced applications. The learners need preliminary knowledge in the principle and basics of digital electronics and computer structure.

Each chapter of the course covers a different resource integrated in the PIC18F45K22 microcontroller on which is based the remote lab employee in the course. All chapters have the same structure.

\section{A. General functional description}

This part presents the resource in a generic way analyzing its main features and purposes. It explores the main theoretical concepts of an operation of the resource from a functional standpoint.

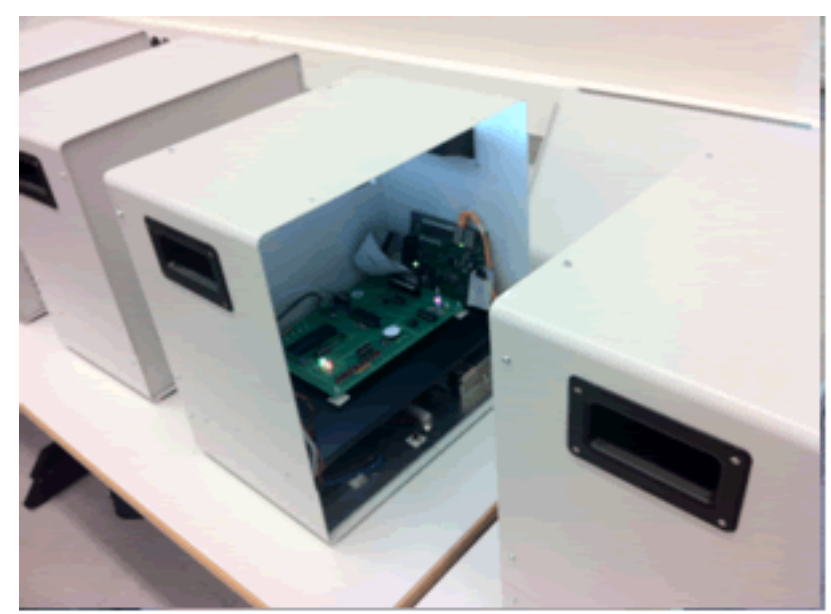

Figure 4. WebLab Deusto PIC into a WebLab Deusto Box.
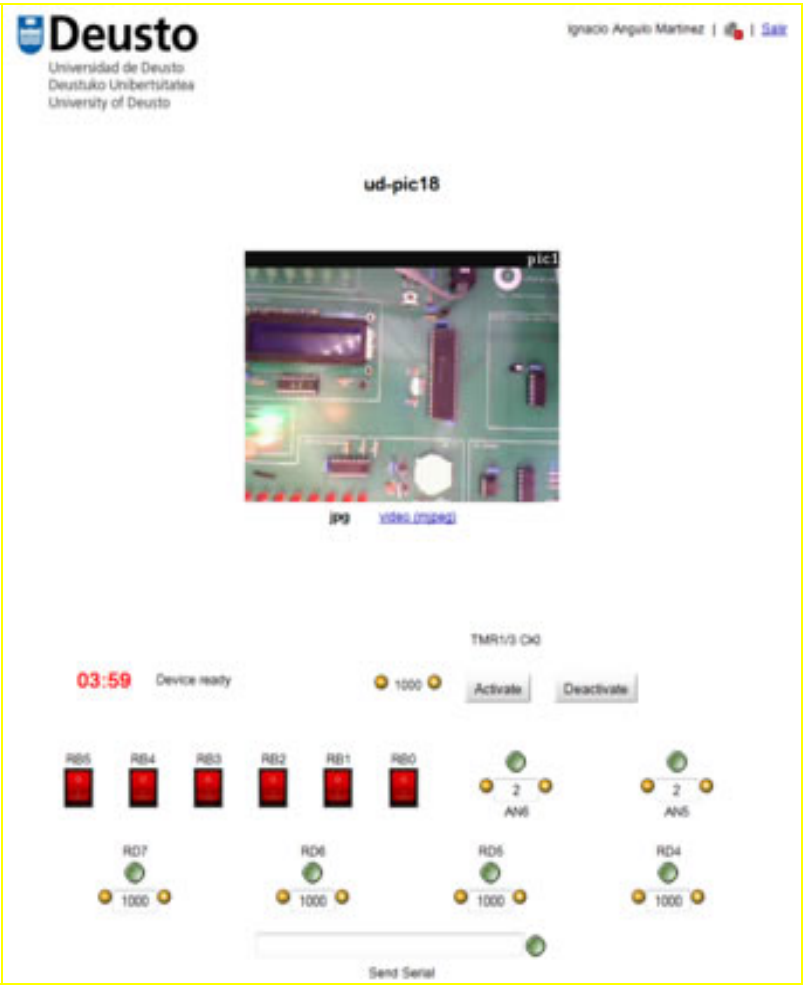

Figure 5. WebLab Deusto PIC Interface.

\section{B. The resurce in the PIC18F45K22}

The second section includes specification of the resource included in the microcontroller "the PIC18F45k22". Based on the manufacturer's datasheet and other published application notes, this section describes the configuration and management of each resource provided.

The focus of the subsequent chapters (resources) provides progressively less assistance as resources are being completed. After the accomplishment of the course students should be able to use any resource integrated into the microcontroller with the sole help of official documentation.

\section{Final Experiment}

Once the resource is properly described, the student is proposing an experiment that must be programmed into a 
microcontroller 18F45k22 actually provided by the remote laboratory WebLab-Deusto PIC.

Initial experiments are offered completely resolved. The provided different solutions and resources will allow increase the part that must be implemented by the student by the end of the course.

The E-PRAGMATIC course "8-bit microcontrollers advanced” covers 4 popular resources:

- Interrupts

- Timers

- Analog to Digital Converter

- Pulse Width Modulation

However, student can experiment with other available resources provided by the remote laboratory WebLabDeusto PIC (Fig.6) [10]. Some other examples including I2C, SPI and UART control are provided to the students over the learning portal.

The course includes a final opened experiment where the student must implement a project integrating at least three resources of the PÎC18F45k22 microcontroller. To complete successfully the course at least one of these resources must be different to the four detailed along the course.

For those participants who have previously completed the course "Introduction to microcontrollers," proposed the challenge task of improving the experiment for guiding the robot along the line using the analog readout of infrared sensors and the motor control through Pulse Width Modulation by dramatically improving the performance obtained in the introductory course.

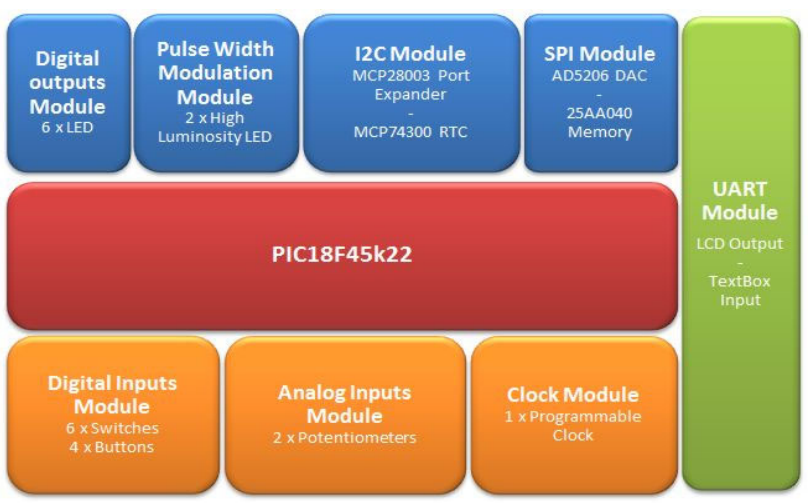

Figure 6. WebLab Deusto PIC Modular Structure.

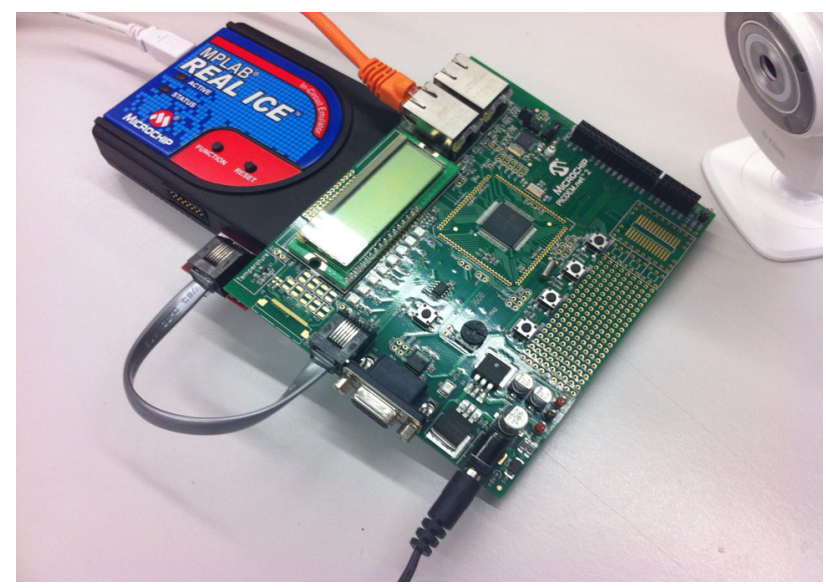

Figure 7. PICDEMNET2 Board used in E-PRAGMATIC course.

\section{LOW-COST PLATFORM TO PROVIDE LAN/WAN} CONNECTIVITY FOR EMBEDDED SYSTEMS

Local area network connectivity has become a primary objective in the design of embedded systems. Most industrial facilities and other administrative and research institutions' buildings, have a deployed local area network that facilitates the installation of new systems without requiring new communication infrastructures. In addition the use of communication standards guarantees the reliability of data transmission and allows the access to the system from different platforms ensuring interoperability. Moreover, if the network is connected to the Internet the embedded system can be remotely controlled or monitored from anywhere in the world.

Until recently, commercial modules for adding embedded systems connectivity to a LAN were complicated, expensive and demanded a large number of materials to the design that caused an increase in hardware size and made it difficult to supply. The proposed learning module reviews the operation of the TCP / IP stack provided for free by the MCU maker Microchip Technology $₫$, which has been able to integrate into a single-chip device a high performance microprocessor and Ethernet controller breaking all the barriers mentioned above. This stack is compatible with the 8,16 and 32 bits Microchip MCUs allowing access to a local area network using the IEEE802.3 (Ethernet) or IEE802.11 (WiFi).

This module includes access to a remote laboratory based on the 18F97J60 PIC microcontroller that will enable students to experiment with all theoretical concepts covered [11], and build an application that allows remotely monitor and control the environmental conditions of an intelligent building. Participants of the course can access through the WebLab-Deusto platform to a virtual machine to experiment with the development board PICDEMNET2 marketed by Microchip. The operation of the same can be observed from a WebCam accessible from the virtual machine. The final project of the course requires creating the experiment - a web application that allows controlling and monitoring 8 LEDs and a temperature sensor integrated at the card PICDEMNET2 from the webpage.

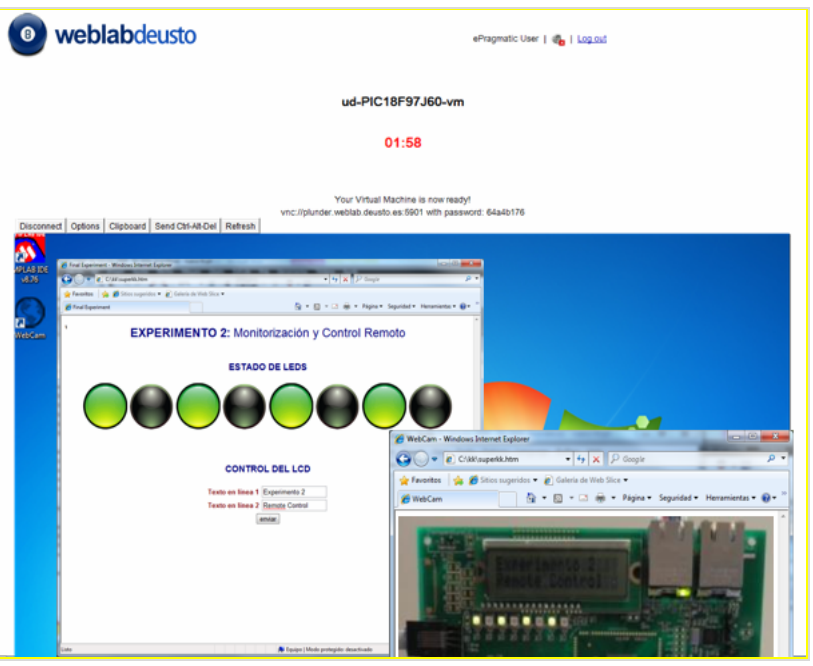

Figure 8. Screenshot of the remote laboratory used in "LOW-COST PLATFORM TO PROVIDE LAN / WAN CONNECTIVITY FOR EMBEDDED SYSTEMS” course 


\section{CONCLUSION}

In the paper the three learning courses for the industry employees in the field of the Microcontrollers were presented. Each course combines a theoretical and practical approach. Such structure of the course allows not only getting contemporary theoretical knowledge in the electronics, but also achieving familiarity in contemporary virtual and remote experimentation. In the first two courses of pilot training 60 participants were overall enrolled. The last one was build on the pedagogical approach "learning by doing" and "learning from mistakes” and, therefore, includes large practical components. It's content consists of $80 \%$ of exercises and project execution. Because of this only 17 participants were invited to take part in pilot training, otherwise the work burden for mentor would be too high. Mostly the participants have been presented by Spanish and international companies, such as National Instruments, ENERGO-ZAP (Poland), IK4-Tekniker (Spain), Telefónica(Spain), Zumbach AG (Switzerland), HAWE Hidravlika d.o.o.(Slovenia),etc. Moreover, several unemployed attendants assigned and finished offered courses. The most participants have mentioned that the content of the training "fulfills my expectations", "difficulty level was adequate", and "knowledge gained in this module will be useful for my further professional carrier", or even "will help to find a job". The pilot training in frame of EPRAGMATIC shows industrial companies needs in enhancement of the employees' knowledge and skills. One of the main results is that cooperation of educational institutions directly with industry yields the results and experience, which are useful for both sides.

\section{ACKNOWLEDGMENT}

This work has been performed within the project "EPRAGMATIC; E-Learning and Practical Training of Mechatronics and Alternative Technologies in Industrial Community", 510586-LLP-2010-SI-LNW. This project is funded with support of the Lifelong Learning Programme of the European Union. All here provided information and documentation reflects the views only of the authors, and the Commission cannot be held responsible for any use which may be made of the information contained therein.

\section{REFERENCES}

[1] New Skills for New Jobs: Action Now - A report by the Expert Group on New Skills for New Jobs prepared for the European Commission, European Commission, February, 2010.

[2] "College to Careers." City Colleges of Chicago. Feb 2012: http://www.ccc.edu/menu/pages/college-to-careers.asp\&xgt;. (accessed March 15, 2012)
[3] EUROPA - EACEA: The Education, Audiovisual and Culture Executive Agency, http://eacea.ec.europa.eu/llp/ (accessed March 15, 2012)

[4] E_PRAGMATIC, http://www.e-pragmatic.eu/ (accessed June 12, 2012)

[5] Rojko A., Hercog D., Jezernik, K. "Distance mechatronics and alternative technologies training for practicing engineers and technicians.” V: Proceedings of the 5th IEEE International Conference on E-Learning in Industrial Electronics Society, pp. 53-58, 2011.

[6] eCampus, http://learning.epragmatic.eu/show.aspx?xid=WBT:X:PrvaStran (accessed 8 Jun 2012)

[7] "Course Structure." Virtual University Design and Technology, Michigan State University. http://vudat.msu.edu/structure (accessed 8 Jun 2012)

[8] Dziabenko O., García-Zubia J., Angulo I., "Time to play with a microcontroller managed mobile bot” In Proceedings of the IEEE International Education Engineering Conference (EDUCON 2012), Marrakesh (Morocco), April 17-20 2012. ISBN: 978-14673-1455-8.

[9] García-Zubia J., Angulo I., Orduña P., Hernández U., Irurzun J., Ruiz J., Castro M., Sancristobal E., "Easily Integrable platform for the deployment of a Remote Laboratory for microcontrollers.” IEEE EDUCON 2010 (ISBN: 978-1-4244-6570-5). 2010.

[10] García-Zubia J., Angulo I., Hernandez U., Orduña P., "Low Cost Remote Lab for Microcontrollers: WebLab-DEUSTO-PIC.” Remote Engineering and Virtual Instrumentation. June, 23rd-25th Dusseldorf, Germany

[11] García-Zubía J, Orduña P., Hernández U., Angulo I., Dziabenko O., Rodriguez-Gil L., López-De-Ipiña. D., "WebLab-DeustoCPLD: A Practical Experience.” WebLab-Deusto-CPLD: A Practical Experience. 1st Experiment@ International Conference (expat2011). 2011.

\section{AUTHORS}

O. Dziabenko is with the University of Deusto, Deusto Tech Learning, Avda de las Universidades 24, 48007 Bilbao (e-mail: olga.dziabenko@ desuto.es).

A. Rojko is with the University of Maribor, Slovenia (e-mail: Andreja.rojko@uni-mb.si).

I. Angulo is with the University of Deusto, Deusto Tech Mobility, Avda de las Universidades 24, 48007 Bilbao (e-mail: ignacio.angulo@deusto.es).

J. Garcia Zubia, is with the University of Deusto, Faculty of Engineering, Avda de las Universidades 24, 48007 Bilbao (e-mail: zubia@deusto.es).

P. Orduna is with the University of Deusto, Deusto Tech Internet, Avda de las Universidades 24, 48007 Bilbao (e-mail: pablo.orduna@deusto.es).

This article is an extended and modified version of a paper presented at the International Conference on Remote Engineering \& Virtual Instrumentation (REV2012), held at University of Deusto, Bilbao, Spain, July 4-6, 2012. Received 14 September 2012. Published as resubmitted by the authors 28 November 2012 . 